Gut, 1971, 12, 729-735

\title{
Clinical evaluation of fibreoptic sigmoidoscopy employing the Olympus CF-SB colonoscope
}

\author{
P. R. SALMON, R. A. BRANCH, C. COLLINS, H. ESPINER, AND A. E. READ \\ From the Department of Medicine, University of Bristol, and the Department of Surgery, Bristol Royal Infirmary
}

SUMMARY Fifty-one patients with large bowel disease were examined with the Olympus CF-SB fibreoptic colonoscope.

With adequate bowel preparation and employing inhalational analgesia administered by a selfdemand valve the whole sigmoid colon could be examined in the majority of patients within 30 minutes.

In $23 \%$ of cases $(12 / 51)$ the diagnosis was either made or confirmed by this procedure alone. Fibreoptic sigmoidoscopy is especially helpful in patients with either equivocal or failed barium enemas and is indicated in patients with unexplained rectal bleeding, extending the search for polyps and cancer, and studying patients with inflammatory bowel disease.

About one quarter of biopsies taken from a flat mucosal surface with the Olympus flexible biopsy forceps may be insufficient for detailed histology due to their small size. For this reason multiple biopsies may be taken. Adequate biopsies were always obtained from projecting lesions and could be very accurately sited. Colour photography employing automatic exposure control is used to supplement the information obtained.

It is concluded that fibreoptic sigmoidoscopy is a valuable additional investigation in selected patients with suspected disease of the large bowel and to date has been without complications.

There is little doubt that the introduction of the fibreoptic gastroscope (Hirschowitz, Curtiss, Peters, and Pollard, 1958) revolutionized investigation of diseases of the stomach. This was soon followed by bulboscopy (Hirschowitz, 1961) and fibreoptic oesophagoscopy (LoPresti, Scherl, Greene, and Farrar, 1962). Continuing evolutionary development of the flexible fibreoptic endoscope has resulted in distal duodenoscopy (Takemoto, 1968) and endoscopic pancreatocholedochography using the Olympus JF-B duodenal fibrescope (Ogoshi, Tobita, and Hara, 1970), whilst the forward viewing system of the A.C.M.I. 7089-A allows not only bulboscopy but also oesophagogastroscopy.

The use of flexible fibreoptic endoscopes for examination of the large bowel has only been exploited during the last few years and is currently undergoing development and evaluation. Initially the end-to-end technique was employed (Provenzale, Camerada, and Revignas, 1966) in which a fibreoptic endoscope was guided into the large bowel along a polyvinyl tube previously positioned by Received for publication 7 June 1971. transintestinal intubation (Colagrande, Arullani, and Casale, 1966).

Total colonoscopy by this technique has little general application due to the tedious and timeconsuming nature of the method. Retrograde colonoscopy under direct vision would appear to be a more generally applicable technique and would enable one if successful to examine the rectum and sigmoid colon, an area involved by more than $80 \%$ of large bowel pathology. Currently available literature emphasizes the value of colonoscopy but does not give sufficient comparative and clinical data to establish this important point beyond doubt. Preparation of the patient usually receives scant attention whilst few authors emphasize the importance for the patient and examiner of adequate analgesia without undue sedation.

We report here clinical details of 52 consecutive colonoscopies performed on 51 patients, with special reference to preparation of the patient, endoscopic technique, and comparison of results with radiology and conventional proctosigmoidoscopy using the rigid instrument. 


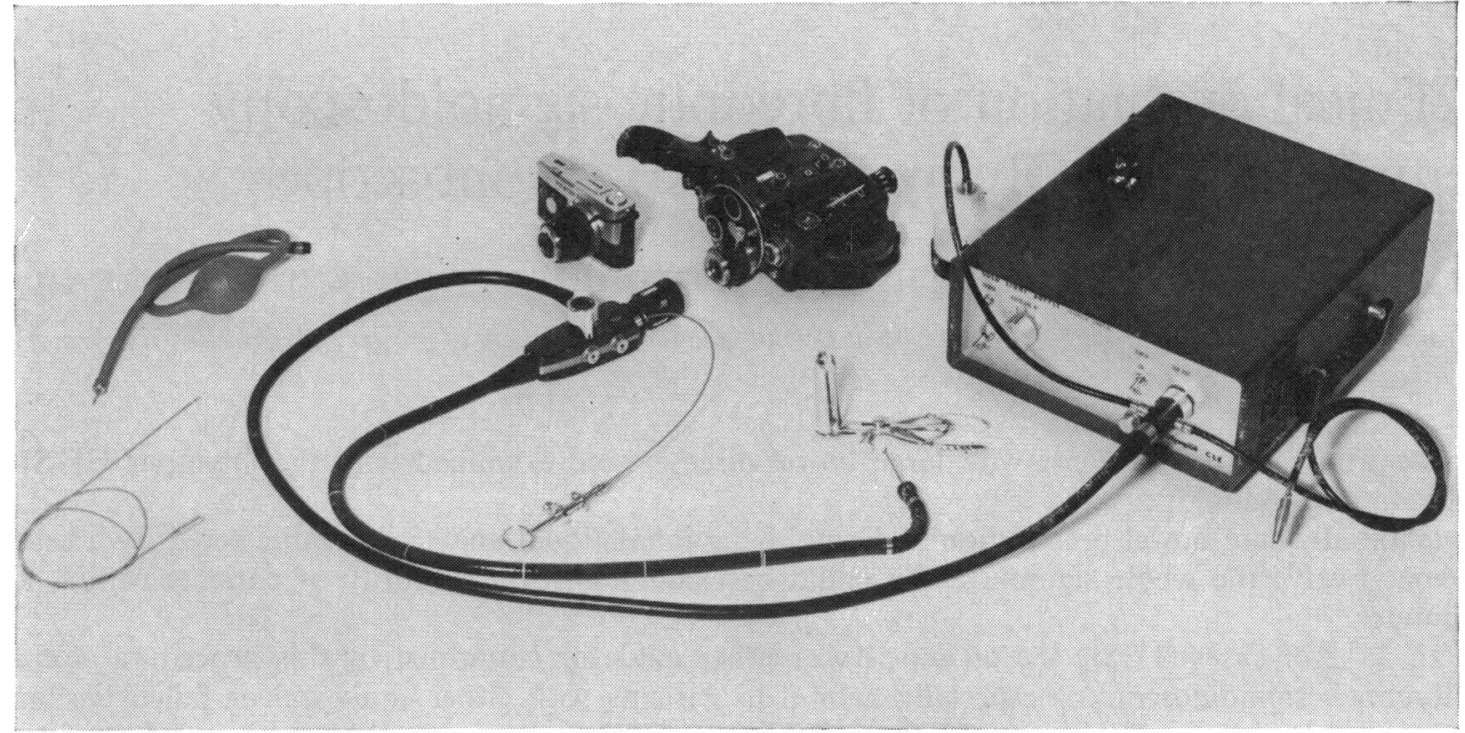

Fig. 1 Olympus CF-SB fibreoptic colonoscope with Beaulieu R16 cine camera.

\section{Instrument}

We have used the Olympus-CF-SB fibreoptic colonoscope (Fig. 1) in this study (Olympus Optical Company, Tokyo; Agents, Key-Med, Southend-onSea). The instrument is $1.2 \mathrm{~cm}$ in diameter and has a working length of $86.5 \mathrm{~cm}$ but can only be passed to a distance of $70 \mathrm{~cm}$. The distal end of the instrument is hinged $4 \mathrm{~cm}$ from the tip and can be manipulated by remote control $120^{\circ}$ upwards and $70^{\circ}$ downwards. This arrangement sometimes allows more acute bends to be negotiated. A halogen quartz lamp housed in a separate box (CLE light source) provides a powerful and variable cold light supply which is transmitted through two fibre bundles to the instrument via a $148 \mathrm{~cm}$ tube. The instrument is provided with a separate viewing bundle and a biopsy channel which accepts flexible biopsy forceps. (A polyvinyl tube may also be passed down the biopsy channel so that water can be directed onto areas requiring local cleansing.) The light source unit is equipped additionally with automatic exposure control. Examinations can be readily recorded photographically by means of the Olympus Pen FT half-frame camera provided. Kodak high speed Ektachrome (EHB 135 Tungsten) film is used. Cine-endoscopy may be performed using the Beaulieu R-16 ('medical') $16 \mathrm{~mm}$ cine camera. ${ }^{1}$ This camera has features making it especially suitable for endoscopic photography, including interlinked emulsion speed and filming speed controls and a ${ }^{1 B}$ Beaulieu Cinema Ltd, 234 Baker Street, London, NW1. ground glass screen with clear central spot. The Olympus colonoscope cine-attachment should be used and allows full frame pictures to be taken. Kodak Ektachrome (EF) film type 7242 (tungsten) is suitable for cine-endoscopy. The CLE light source is satisfactory for close-up work using full power, although longer shots usually require a slower film speed. Alternatively the film may require forced developing. The Olympus extra-high intensity cold light source model CLS is especially suitable for cine-endoscopy work. A built-in pump provides either air for bowel inflation, water or other fluid for cleansing the lens during the examination, and a line for attachment to an external suction apparatus. These facilities are controlled by valves which can be operated by one hand.

A Higginson syringe and brush are provided for cleaning the biopsy channel.

\section{Patients Studied}

Fifty-two examinations were performed on 51 patients (Table I). In 21 patients a presumptive diagnosis had been made before colonoscopy and this examination was performed not only to obtain biopsy and photographic evidence of disease but also to study the extent of the disease.

In 30 patients ( 31 examinations) colonoscopy was performed in order to clarify or supplement routine investigations where these had failed to produce unequivocal evidence of disease.

Before this series 15 examinations were performed 


\begin{tabular}{lrr}
\hline Diagnosis before Examination & & Patients Studied \\
\hline Proctocolitis & 14 & 20 \\
Crohn's disease (colon) & 3 & \\
Neoplasia & 3 & \\
& & \\
Unexplained weight loss & 3 & \\
Unexplained diarrhoea & 5 & 31 \\
Rectal bleeding (undiagnosed) & 4 & \\
Constipation & 1 & \\
Irritable bowel syndrome & 4 & \\
Diverticular disease & 3 & \\
Abdominal pain & 1 & \\
Mass in left iliac fossa & 1 & \\
Equivocal barium enema & 6 & \\
Failure to retain barium & 3 & \\
\hline
\end{tabular}

Table I Fibreoptic colonoscopy on 51 patients

under $x$-ray control in order to familiarize ourselves with the instrument and technique.

In one patient with large bowel Crohn's disease who had had a right hemicolectomy and ileotransverse anastomosis, a barium enema revealed the possibility of an ileo-colic fistula (Fig. 2). This was confirmed by colonoscopy.

\section{Preparation of the Patient}

In order to carry out a satisfactory large bowel examination, preparation of the patient must satisfy certain conditions. These include bowel preparation, sedating the patient to permit his cooperation, analgesia, and freedom from abdominal muscular rigidity. In addition, adequate vagal protection should be present to prevent reflex cardiac arrhythmias (Fletcher, Earnest, Schuford, and Wenger, 1968).

Thirty-seven of 51 patients had two colon washouts: one was carried out the night before the examination and the second one between one and two hours before the procedure. Up to 6 litres of warm tap water was generally employed.

Seven of 51 patients with semiformed stools had one bowel washout between one and two hours before the examination.

Eight of 51 patients had no bowel preparation. These were patients with watery diarrhoea. All patients were instructed to have a bowel action immediately before the examination.

Premedication was employed using a variety of sedative and analgesic drugs in the first 24 patients. These included pethidine ( 5 cases), pethidine and chlorpromazine (5 cases), sodium amylobarbitone (3 cases), tranylcypromine (1 case), diazepam (1 case), general anaesthesia (1 case). Eight patients had no premedication. Probanthine $(30 \mathrm{mg}$ im) was employed where spasm appeared to limit the extent of examination. This proved necessary in two cases. In an attempt to increase the degree of spoken contact with the patient a further 26 examinations

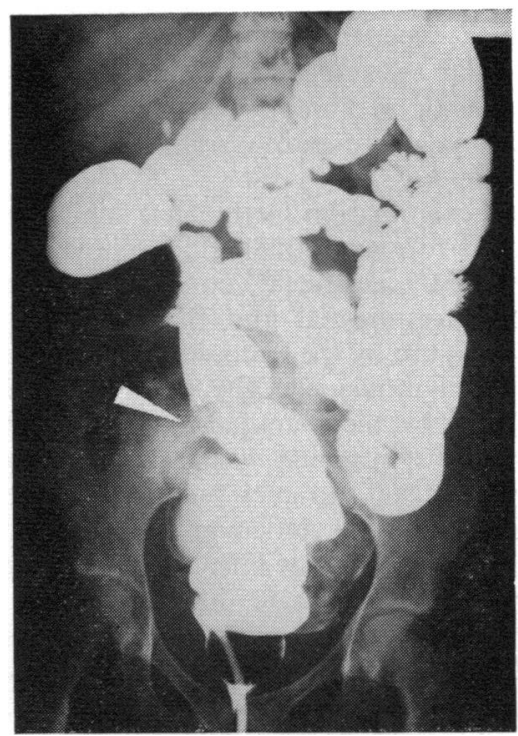

Fig. 2 Barium enema (case 3) indicating suspected ileo-colic fistula.

were performed using premixed nitrous oxide and oxygen (Entonox, British Oxygen Company) selfadministered using a demand valve and without further premedication.

The patient was instructed in the use of the demand valve and the importance of obtaining a good airtight fit between the mask and his face. One minute of inhalation was allowed before attempting colonoscopy. This allowed the maximum analgesic effect of the gas to be obtained.

The degree of discomfort, cooperation, and extent of examination was recorded in each patient following colonoscopy. In 43 of 51 cases proctosigmoidoscopy using the rigid instrument served as a yardstick with which to compare the degree of discomfort associated with colonoscopy.

Continuous ECG monitoring was performed in all 26 patients using Entonox and in 12 of the 24 patients in whom other drugs were used.

\section{Endoscopic Technique}

The colonoscope was allowed to reach room temperature and the lens and fibre bundle were siliconed before use. Glycerine or a water-soluble jelly were used to lubricate the distal $10 \mathrm{~cm}$ of the endoscope. The patient's name and hospital number were photographed through the colonoscope. Patients were either preme ticat $2 d$ or instructed in the use of the self-demand apparatus for Entonox. All patients were examined initially in the left lateral 
position. Previous experience of colonoscopy had shown no particular advantage of continuous $x$-ray control, and exposure of fibreoptic instruments to $x$-rays should be avoided due to irradiation damage to the fibre bundle.

Careful digital examination of the anal sphincter and canal was performed initially to exclude the presence of painful ano-rectal conditions. The instrument was then inserted into the rectum by exerting gentle pressure by the endoscope tip on the anal sphincter until it relaxed. The trivalve rectal speculum provided by the manufacturers was not found helpful. Further progress was carried out by a combination of distal tip manipulation, gentle pressure, and rotation. All manoeuvres were carried out under direct vision. Air was introduced into the bowel when required to facilitate the examination. In the majority of cases the whole examination was performed in the left lateral position but occasionally the lithotomy position was found necessary. Manipulation of the instrument by the hand through the abdominal wall was not often found to be helpful.

\section{Results}

\section{PREPARATION OF THE PATIENT}

Bowel preparation was judged satisfactory in 47 of 52 examinations. In the five cases in which it was not the extent of the examination was limited by the presence of faeces.

There was little doubt that Entonox was superior to non-inhalational analgesics, not only with respect to the degree of analgesia and cooperation of the patient (Bennett, Salmon, Branch, Baskett, and Read, 1971) but in allowing a greater extent of bowel to be examined. Twelve of $24(50 \%)$ patients not receiving Entonox experienced severe discomfort, whilst one patient who had had pethidine became confused, curtailing the examination. Of 26 patients receiving 50/50 nitrous oxide/oxygen, 23 experienced relief of discomfort. In three the outcome was not satisfactory due to a poorly fitting mask, failure to obtain relief despite correct inhalation, and hysteria. Both the latter two cases were receiving psychiatric treatment. ECG monitoring failed to reveal any arrhythmias in those receiving Entonox. In one patient who received no premedication ventricular extrasystoles were noted.

EXTENT OF EXAMINATION

Conventional proctosigmoidoscopy (Lloyd-Davies sigmoidoscope) in 43 cases showed that on average only the rectum had been examined $(14 \cdot 6 \pm 2 \cdot 8 \mathrm{~cm})$. The extent of the bowel examined by colonoscopy was much greater but showed a significantly greater length examined when Entonox was used (53.7 \pm
$14.0 \mathrm{~cm})$ as opposed to non-inhalational analgesics $(43 \cdot 1 \pm 20 \cdot 1 \mathrm{~cm})$. The clinical impression that the more rigid inflamed bowel of Crohn's disease or ulcerative colitis allowed a greater extent of bowel to be examined was confirmed by the results (inflammatory bowel disease $53.7 \pm 16.1 \mathrm{~cm}$, normal bowel $44 \cdot 8 \pm 18 \cdot 3 \mathrm{~cm}$ ). The instrument was passed beyond $60 \mathrm{~cm}$ in 15 examinations $(29 \%)$. In a further four cases no attempt was made to extend the examination due to the discovery of pathology (Table II). In all these cases it was clear that the descending colon had been reached. The average time taken to complete these examinations was $\mathbf{3 0}$ minutes. In the remaining cases it was usually apparent by 30 minutes that the examination was unlikely to extend to the splenic flexure (usually about $70 \mathrm{~cm}$ ).

No attempt was made in this study to employ the technique of Deyhle (1970) in which, using the longer Olympus CF-LB colonoscope and $x$-ray control it is possible to straighten out the sigmoid loop(s) and perform total colonoscopy.

\section{RADIOLOGY}

Barium enemas were performed on all patients using a standard procedure employing barium sulphate. Tannic acid was omitted in cases where proctocolitis was suspected or colic had occurred.

Special efforts were made to obtain good quality outlet and post-evacuation films. In cases where the mucosal pattern was of insufficient quality for a radiological opinion a double-contrast enema was performed.

In six of 51 patients an equivocal radiological diagnosis was made (Table II). In each case colonoscopy established the nature of the suspected lesion.

\section{BIOPSIES}

The flexible biopsy forceps provided with the instrument have two hemispherical blades, each $1.3 \mathrm{~mm}$ in length. Both these blades open and are easily operated by one hand. Forty-one biopsies were taken in 21 patients during this study. Of the 21 patients

\begin{tabular}{|c|c|c|c|}
\hline Patient & Sex & X-Ray Diagnosis & Colonoscopy \\
\hline $\begin{array}{l}\text { D.M. } \\
\text { L.G. }\end{array}$ & $\begin{array}{l}\mathbf{F} \\
\mathbf{F}\end{array}$ & $\begin{array}{l}\text { Annular carcinoma rectum } \\
\text { Crohn's colon, ileo-colic } \\
\text { fistula }\end{array}$ & $\begin{array}{l}\text { Normal rectum } \\
\text { Confirmed }\end{array}$ \\
\hline $\begin{array}{l}\text { A.B. } \\
\text { J.S. } \\
\text { D.P. } \\
\text { D.S. }\end{array}$ & $\begin{array}{l}\mathbf{F} \\
\mathbf{F} \\
\mathbf{F} \\
\mathbf{F}\end{array}$ & $\begin{array}{l}\text { Sigmoid neoplasm } \\
\text { Sigmoid neoplasm } \\
\text { Sigmoid polyp } \\
\text { Sigmoid polyp }\end{array}$ & $\begin{array}{l}\text { Normal sigmoid } \\
\text { Confirmed } \\
\text { Confirmed } \\
\text { Ulcerative colitis, no } \\
\text { polyp seen }\end{array}$ \\
\hline
\end{tabular}

Table II Colonoscopic findings in patients with equivocal barium enemas 
biopsied, six of eight cases of polyps seen endoscopically (Table III) were successfully biopsied (histological diagnosis). In the other two the material obtained was too scanty for diagnosis. In both cases, however, there was little doubt as to the correct diagnosis from the endoscopic appearance. In four further cases the biopsy material was insufficient for a full histological diagnosis.

\begin{tabular}{lll}
\hline & $\begin{array}{l}\text { Conventional } \\
\text { Investigations }\end{array}$ & Colonoscopy \\
\hline Inflammatory & 2 & 4 \\
Malignant & 1 & 1 \\
Adenomatous & 1 & 2 \\
Metaplastic & & 1 \\
Total & 4 & 8 \\
\hline
\end{tabular}

Table III Demonstration of polyps

\section{Case Histories}

The following cases illustrate the value of fibreoptic colonoscopy.

CASE 1

D.S. (F), aged 63, complained of intermittent rectal bleeding and loose motions for one year.

Conventional proctosigmoidoscopy performed in the Outpatients Department and subsequently under anaesthesia showed a mild proctitis. Barium enema examination showed a round, translucent shadow in the sigmoid (Fig. 3). This was present on all films. Fibreoptic colonoscopy demonstrated severe colitis to $50 \mathrm{~cm}$. There was no evidence of a sigmoid polyp, suggesting that the radiological shadow was an artefact.

\section{CASE 2}

D.P. (F), aged 66, complained of intermittent rectal bleeding for one year. A barium enema demonstrated the possibility of a pedunculated polyp in the sigmoid colon (Fig. 4). Conventional proctosigmoidoscopy was only possible to $14 \mathrm{~cm}$. Fibreoptic colonoscopy showed a pedunculated polyp $3 \mathrm{~cm}$ in length with its base at $25 \mathrm{~cm}$ (Fig. 5).

\section{CASE 3}

L.G. (F) aged 23, with established Crohn's disease had had a right hemicolectomy and ileo-transverse anastomosis. A barium enema suggested the presence of an ileo-colic fistula (Fig. 2). Fibreoptic colonoscopy performed in order to survey the remaining large bowel demonstrated a fistula at $26 \mathrm{~cm}$.

\section{Overall Value of Colonoscopy}

In this series 12 of 51 cases $(23 \cdot 3 \%)$ had significant

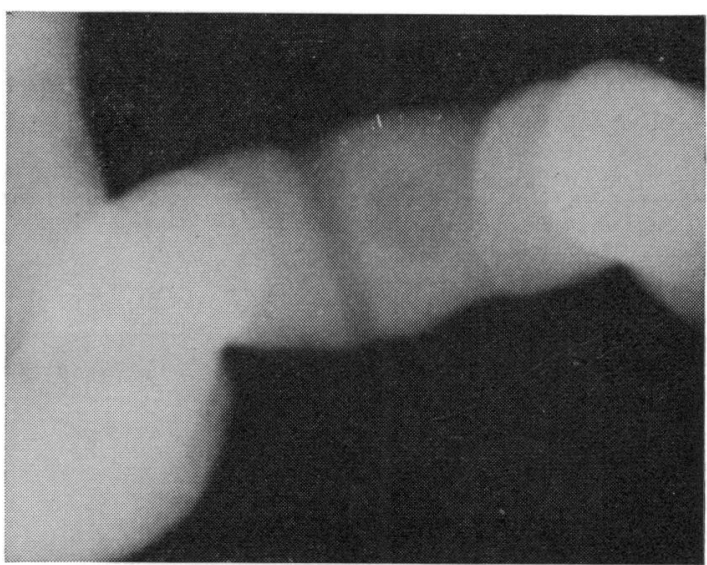

Fig. 3 Sigmoid colon (case 1) showing round translucent shadow.

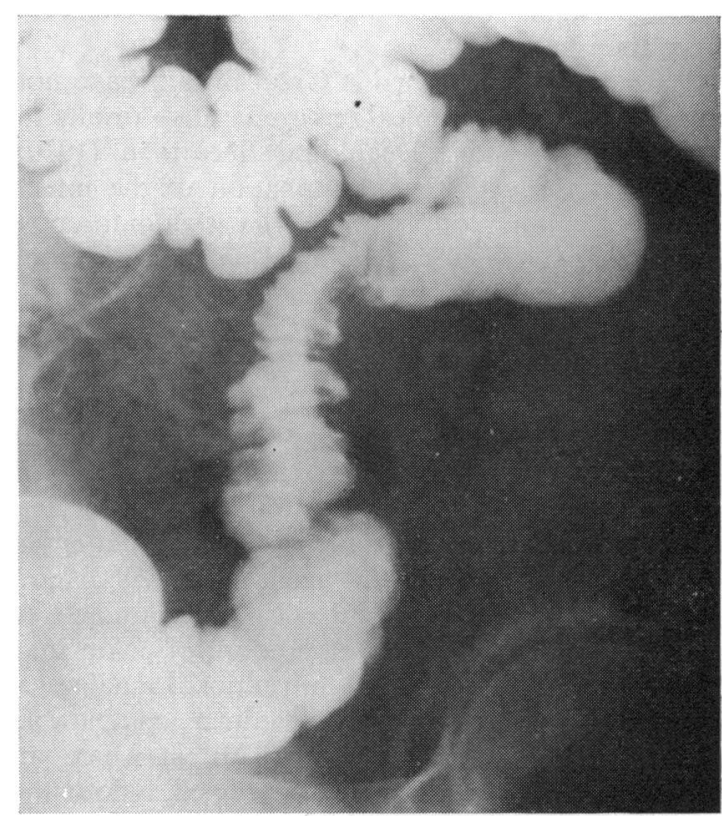

Fig. 4 Barium enema (case 2) showing polypoid filling defect in the sigmoid colon.

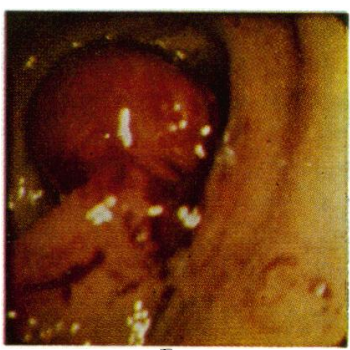

Fig. 5 Pedunculated sigmoid polyp (case 2). 
large bowel disease diagnosed by colonoscopy alone (Table IV). In six of these cases $(11.5 \%)$ colonoscopy established the nature of equivocal radiographs.

\begin{tabular}{|c|c|c|c|c|c|c|c|}
\hline $\begin{array}{l}\text { Unsus } \\
\text { Polyps } \\
\text { Equiv }\end{array}$ & $\begin{array}{l}\text { cted inflamma } \\
\text { ee Table IV) } \\
\text { l barium ene }\end{array}$ & $\begin{array}{l}\text { tory di } \\
\text { ma (see }\end{array}$ & $\begin{array}{l}\text { sease } \\
\text { Table }\end{array}$ & $\begin{array}{c}\ddot{.} \\
\text { III) }\end{array}$ & $\begin{array}{l}\cdots \\
\cdots \\
\cdots\end{array}$ & $\begin{array}{l}\cdots \\
\cdots \\
\cdots\end{array}$ & $\begin{array}{l}2(4 \%) \\
4(7.8 \%) \\
6(11.5 \%)\end{array}$ \\
\hline Total & $\cdots$ & . & $\cdots$ & $\cdots$ & $\cdots$ & $\cdots$ & $12(23.3 \%)$ \\
\hline
\end{tabular}

Table IV Findings attributable solely to colonoscopy

\section{Discussion}

Wider use of the flexible fibreoptic endoscope in the investigation of large bowel disease is overdue. Part of this delay is due to the relatively high cost of these instruments (about $£ 1,500$ ) which must be weighed against the economic advantages resulting from their use.

Current data published in Great Britain have not provided sufficient clinical or comparative results to make this decision. Dean and Shearman (1970) compared the extent of examination of the intact colon by colonoscopy with routine sigmoidoscopy in 21 cases but only gave clinical data in one case. Their data showed that in over half of these cases only a small part of the sigmoid colon was examined, thus casting doubt on the value of the procedure.

In this study we have shown the importance of the preparation of the patient and in particular the advantage of obtaining full analgesia using premixed nitrous oxide and oxygen (Entonox) but preserving spoken contact with the patient. Statistical analysis suggests that the use of this agent alone will extend the amount of large bowel that can be examined. It is possible that the increased amount of colon that could be examined with conventional analgesics $(43 \cdot 1 \pm 20 \cdot 1 \mathrm{~cm})$ compared with a comparable group (Dean and Shearman, 1970), in which an average of $30 \mathrm{~cm}$ of bowel was examined, reflects the earlie experience that we obtained before this series.

Adequate vagal protection would seem to be important. Fletcher, Earnest, Shuford, and Wenger (1968) found that of 100 patients given proctosigmoidoscopies, 26 developed reflex cardiac arrhythmias, whilst 32 developed ECG changes without arrhythmias. In this series, one of 38 patients monitored for cardiac arrhythmias developed transient ventricular extrasystoles. This subject had received no premedication. We conclude that premixed nitrous oxide and oxygen provides sufficient vagal protection during colonoscopy. There were no complaints of chest pain throughout this series.

Endoscopic technique is to some extent an

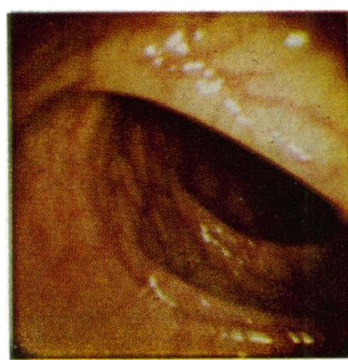

Fig. 6.

Fig. 6 Normal sigmoid colon as seen with colonoscope, showing depth of focus.

Fig. 7 Normal sigmoid colon as seen with colonoscope showing details of vascular pattern.

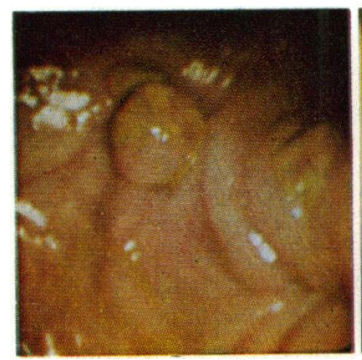

Fig. 8.

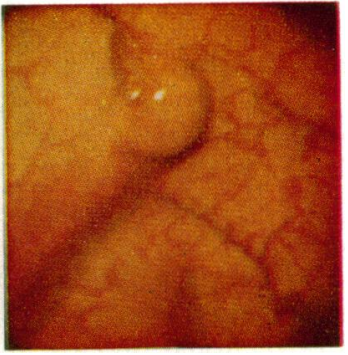

Fig. 9.

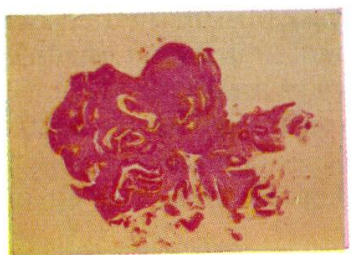

Fig. 10.

Fig. 8 Metaplastic sigmoid polyp.

Fig. 9 Adenomatous polyp (sigmoid).

Fig. 10 Biopsy $(\times 16)$ of previous polyp using Olympus biopsy forceps.
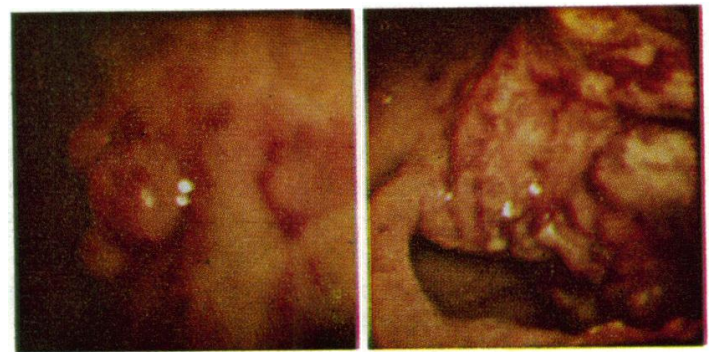

Fig. 11.

Fig. 12.

Fig. 11 Inflammatory pseudopolyps (rectum).

Fig. 12 Carcinoma of rectum. 
individual problem. Some commence the procedure in the left lateral position (Fox, 1970), whilst others use the lithotomy position throughout (Niwa, 1970). We have found that the left lateral position is usually satisfactory for the whole examination.

The examining position is to some extent limited when $x$-ray screening is employed. We do not find screening helpful but would recommend its use only to familiarize oneself with the instrument and technique. Continued use of $x$-ray control is to be avoided since the fibres eventually discolour and suffer permanent damage.

Bowel preparation is of considerable importance. Overholt (1970) recommends 3 tablets of bisacodyl (Dulcolax) the night before the procedure, whilst Niwa (1970) employs $25 \mathrm{ml}$ of castor oil. This latter measure appears to be unduly drastic. Bowel washouts if efficiently performed are usually satisfactory. These can be modified or dispensed with altogether in the presence of diarrhoea.

Great importance is attached by some investigators to the technique of total colonoscopy. Visualization of the right colon and caecum is only rarely required. We consider that the importance of examining the upper sigmoid endoscopically in almost every patient should not be overlooked. Since more than threequarters of all large bowel disease may be found in the rectum and sigmoid colon, the importance of full sigmoidoscopic examination should not be underestimated.

We consider that the chief indications for fibreoptic colonoscopy include the diagnosis of rectal bleeding of unknown cause, extending the search for polyps, excluding sigmoid cancer, and assisting in the interpretation of equivocal radiographs.

Biopsies taken with the Olympus biopsy forceps tend to be small and in some cases adequate histological material is not obtained. We have found that projecting lesions or mucosa can nearly always be biopsied to the pathologists' satisfaction (Fig. 10). When taking a biopsy from a flat mucosal surface the forceps are advanced in the 'open' position on to the mucosa until dimpling occurs. Some degree of judgment is required here not only to avoid taking too small a biopsy but also to avoid perforating the bowel. We have not encountered this complication.

We conclude that fibreoptic colonoscopy, by extending conventional proctosigmoidoscopy so that total sigmoidoscopy can be performed in nearly every subject, represents a major advance in the investigation of large bowel disease.

We would like to thank Dr D. R. Coles, Professor A. G. Riddell, and Mr W. K. Eltringham for referring cases to us.

We also thank Dr J. Roylance and Dr R. J. Burwood for advice on radiological problems.

We thank Mr J. Eatough for skilled photographic help and advice.

References

Bennett, J. A., Salmon, P. R., Branch, R. A., Baskett, P. J. F., and Read, A. E. A. (1971). The use of inhalational analgesia during fibre-optic colonoscopy. Anaesthesia, 26, 294-297.

Colagrande, C., Arullani, P., and Casale, C. (1966). A suction biopsy procedure for obtaining specimens of mucosa from the right and left colon. Amer. J. dig. Dis., 11, 389-393.

Dean, A. C. B., and Shearman, D. J. C. (1970). Clinical evaluation of a new fibreoptic colonoscope. Lancet, 1. 550-552.

Deyhle, P. (1970). Personal communication.

Fletcher, G. F., Earnest, D. L., Shuford, W. F., and Wenger, N. K. (1968). Electrocardiographic changes during routine sigmoidoscopy. Arch. intern. Med., 122, 483-486.

Fox, A. (1970). Personal communication.

Hirschowitz, B. I. (1961). Endoscopic examination of the stomach and duodenal cap with the fiberscope. Lancet, 1, 1074-1078.

Hirschowitz, B. I., Curtiss, L. E., Peters, C. W., and Pollard, H. M. (1958). Demonstration of a new gastroscope, the "fiberscope". Gastroenterology, 35, 50-53.

LoPresti, P., Scherl, N. D., Greene, L., Farrar, J. T. (1962). Clinical experience with a glass fiber-gastroscope. Amer. J. dig. Dis., 7, 95-101.

Niwa, H. (1970). Personal communication.

Ogoshi, K., Tobita, Y., and Hara, Y.(1970). Endoscopic observation of the duodenum and pancreato-choledochography using duodenal fiberscope under direct vision. Gastroent. Endosc. (Tokyo), 12, 1, 83-96.

Overholt, B. F. (1970). Instructions for A.C.M. flexible sigmoidoscope. American Cystoscope Makers Inc.

Provenzale, L., Camerada, P., and Revignas, A. (1966). La coloscopia totale transanale mediante una metodica originale. Radd med. Sarda, 69, 149-160.

Takemoto, T. (1968). Direct vision observation of the duodenal mucous membrane, Part I. Gastroent. Endosc. (Tokyo), 10, 253. 